\title{
Sensitivity of Seedling Radicles to Chilling and Heat- shock-induced Chilling Tolerance
}

\author{
Abdur Rab and Mikal E. Saltveit \\ Mann Laboratory, Department of Vegetable Crops, University of California, Davis CA 95616-8631 \\ Additional key words. corn, cucumber, Cucumis sativus, germination, Hibiscus esculentus, Lycopersicum esculentum, mung \\ bean, lateral roots, seeds, temperature, tomato, okra, Phaseolus aureus, Zea mays
}

\begin{abstract}
The sensitivity of corn, cucumber, mung bean, and tomato seedling radicles to chilling (i.e., inhibition of subsequent elongation at $25 \mathrm{C}$ after chilling at $2.5 \mathrm{C}$ ) was greater for radicles 5 to $7 \mathrm{~mm}$ long than for radicles $1 \mathrm{~mm}$ long. In contrast, radicles of germinating okra seeds had a similar level of chilling inhibition (i.e., $70 \%$ to $90 \%$ ) at lengths of 1 to $7 \mathrm{~mm}$. For seeds with 1-mm-long radicles, subsequent radicle elongation for cucumber was inhibited only $2 \%$ by 72 hours of chilling at $2.5 \mathrm{C}$, while it was inhibited about $20 \%$ for corn, mung bean, and tomato. For seeds with 5- to 7-mmlong radicles, chilling inhibition was $50 \%$ to $70 \%$ for corn, mung bean, and tomato and $80 \%$ to $90 \%$ for cucumber and okra. The degree of chilling sensitivity varied among species in relation to time required to elicit a significant response and the magnitude of the elicited response. The development of lateral roots decreased with prolonged chilling in all species. Heat shock (i.e., 4 to 10 minutes at $45 \mathrm{C}$ ) induced chilling tolerance in all species except okra. In okra, neither increasing the heat-shock temperature nor decreasing the severity of chilling (i.e., temperature and duration of exposure) significantly reduced chilling injury.
\end{abstract}

Many important crops of tropical and temperate origin, such as corn, cotton, cucumbers, rice, soybeans, squash, and tomato, are injured when exposed to nonfreezing temperatures below $12 \mathrm{C}$ (Bramlage, 1982; Lyons et al., 1979; Saltveit and Morris, 1990). Symptoms of chilling injury include reduced seed germination, seedling growth and viability, and increased permeability of cellular membranes, disease susceptibility, and production of carbon dioxide and ethylene. The extent of injury varies with the species and cultivar (Cabrera et al., 1992; Kapitsimadi et al., 1991), and with the method used to measure it. For example, a significant reduction in cucumber seedling radicle elongation occurred after only $24 \mathrm{~h}$ of chilling at $2.5 \mathrm{C}$, while a significant increase in ion leakage occurred after only $48 \mathrm{~h}$ of chilling (Rab and Saltveit, 1996). Subsequent radicle elongation is a more sensitive indicator of chilling injury than is ion leakage or the production of carbon dioxide or ethylene.

A number of treatments reduce symptom development by either increasing the tolerance of tissues to chilling or by eliminating the stress that causes symptom development after chilling. For example, increasing the relative humidity around the tissue after chilling ameliorates the development of symptoms dependent on water loss (Minorsky, 1985). Treatments such as heat shocks (Collins et al., 1993; Jennings and Saltveit, 1994a; Saltveit, 1991) and intermittent warming (Carbrera and Saltveit, 1990) appear to increase the tolerance of the tissue to the primary event(s) of chilling.

Heat shocks induce tolerance in plants and animals to high temperatures that would have been lethal (Vierling, 1990). Heat shocks also confer tolerance to chilling temperatures in cucumber cotyledons (Lafeuenta et al., 1991), cucumber radicles (Jennings and Saltveit, 1994a; Rab and Saltveit, 1996), mung been hypocotyls (Collins et al., 1993), and tomato fruit (Lurie and Klien, 1991). The induction of heat-shock proteins has been reported in chilling tolerant species such as pea (Mansfield and Key, 1987) and in sensitive species such as cotton (Burke et al., 1985), cucumber

Received for publication 7 Nov. 1995. Accepted for publication 20 Feb. 1996. The cost of publishing this paper was defrayed in part by the payment of page charges. Under postal regulations, this paper therefore must be hereby marked advertisement solely to indicate this fact.
(Lafeuenta et al., 1991), mung bean (Chen et al., 1986; Collins et al., 1995), tobacco (Meyer and Chartier, 1983), and tomato (Lurie and
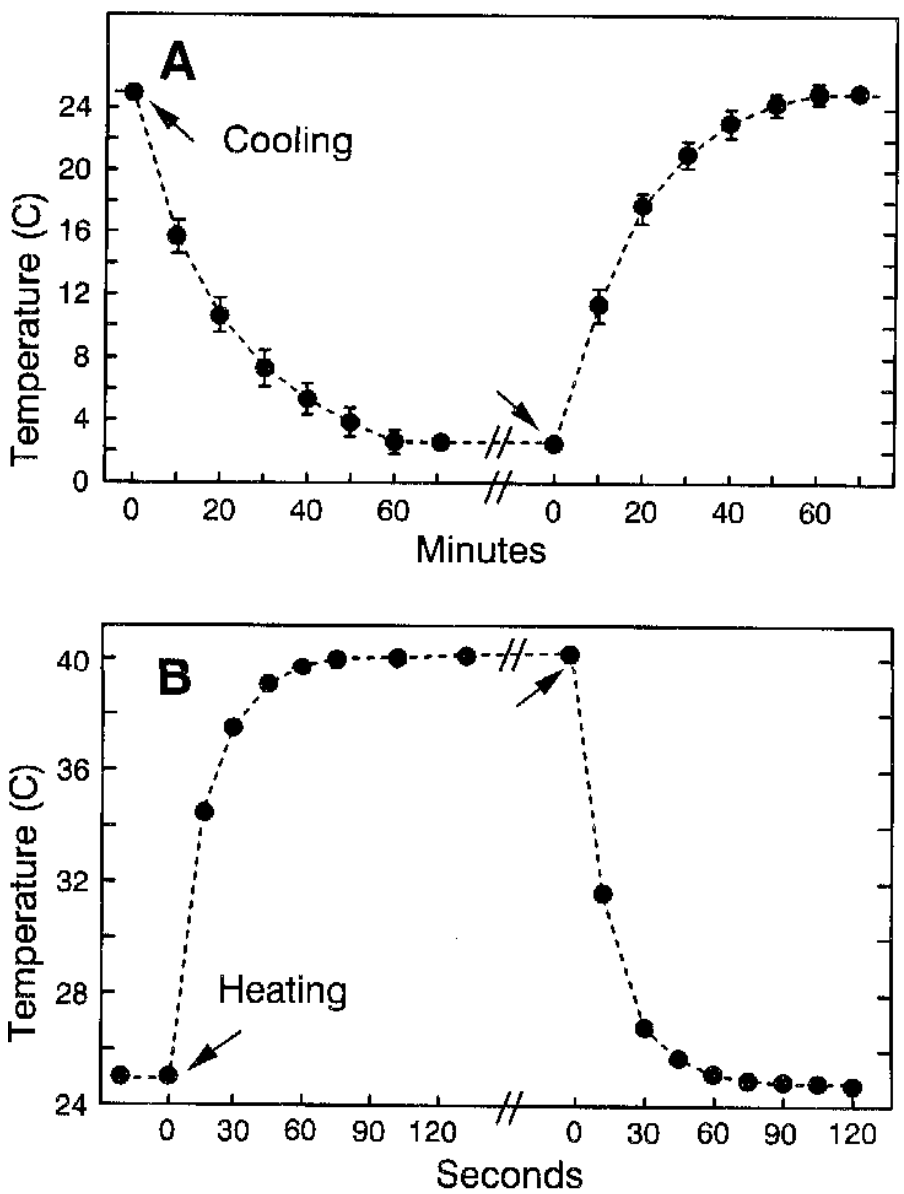

Fig. 1. Kinetics of applied heat shock and chilling treatments. (A) Cooling and heating kinetics for cucumber seedlings in Plexiglas sandwiches transferred from 25 to 2.5 $\mathrm{C}$ and then back to $25 \mathrm{C}$. (B) Heating and cooling kinetics for cucumber seedlings in petri dishes taken from $25 \mathrm{C}$ and floated on $40 \mathrm{C}$ water, and then put back at 25 C. The vertical bars represent the standard deviations about the means $(n=5)$. Where there are no vertical bars, the standard deviation is within the symbol. 
Klein, 1991; Nover and Scharf, 1984). In mung bean hypocotyl tissue, exposure to $50 \mu \mathrm{M}$ cycloheximide during and after the heatshock treatment drastically reduced both the amount of protein synthesized and the degree of chilling tolerance induced (Collins et al., 1993, 1995). These data suggest that de novo protein synthesis may be required for heat-shock induced chilling tolerance.

This study investigated the effects of chilling on seedling radicles of a number of diverse crop species, and the ability of heat shock to confer chilling tolerance to these seedling radicles.

\section{Materials and Methods}

Plant material. Seeds of corn (Zea mays L. 'Jubilee' hybrid), cucumber (Cucumis sativus L., 'Poinsett 76'), mung bean (Phaseolus aureus, Roxb., 'Berkin'), okra(Hibiscus esculentus L., 'Clemson Spineless'), and tomato (Lycopersicum esculentum Mill., 'Rio Grande') were obtained from local vendors. After imbibition in aerated water overnight at $25 \mathrm{C}$, the seeds were transferred to moist paper toweling sandwiched between two $15 \times 30-\mathrm{cm}$ Plexiglas plates that were held together with rubber bands. The seeds were oriented with the radicle down and the units were kept in a vertical position at $25 \mathrm{C}$ in a humid, ethylene-free atmosphere until the radicles reached the appropriate length. Fifteen seedlings with radicles of the appropriate length were then transferred to each of three $7 \times 13-\mathrm{cm}$ Plexiglas plates that were assembled as before. These units were then subjected to the various treatments.

Temperature treatments. The Plexiglas units were positioned to ensure unrestricted air movement around them. Cucumber seeds in the center of the units cooled from 25 to $2.5 \mathrm{C}$ or warmed from 2.5 to $25 \mathrm{C}$ in $60 \pm 5 \mathrm{~min}$ (Fig. 1A). Germinating seeds were heatshocked by transferring them from the Plexiglas units to petri dishes containing one layer of filter paper wetted with $2 \mathrm{ml}$ of water. The dishes were heated by floating them on water at 40, 45, or $50 \mathrm{C}$ for 0 to $10 \mathrm{~min}$. Cucumber seeds in the center of the dish were heated from 25 to $40 \mathrm{C}$ or cooled from 40 to $25 \mathrm{C}$ in $60 \pm 7$ s (Fig. 1B).

Measures of chilling injury. Chilling injury was measured as the inhibition of subsequent radicle elongation at $25 \mathrm{C}$ for $72 \mathrm{~h}$ (Jennings and Saltveit, 1994b). Radicle length was measured with a clear ruler to the nearest $\mathrm{mm}$ through the transparent Plexiglas immediately after the temperature treatment and after $72 \mathrm{~h}$ at $25 \mathrm{C}$. Measurements at 24 and $48 \mathrm{~h}$ were used to establish the kinetics of radicle elongation.

Relationship between radicle length and chilling sensitivity. The relationship between chilling sensitivity and radicle length was determined by transferring seeds with 1-, 3-, 5-, or 7-mm-long radicles to the $13 \times 7-\mathrm{cm}$ Plexiglas plates. The seeds were chilled at $2.5 \mathrm{C}$ for $72 \mathrm{~h}$ and subsequent elongation was measured after 72 $\mathrm{h}$ at $25 \mathrm{C}$.

Effects of temperature and duration of exposure on subsequent elongation. Germinating seeds with radicles at the sensitive length identified in the previous experiments were kept at 2.5, 5.0, 7.5, $10.0,12.5$, or $15 \mathrm{C}$ for $0,24,48$, or $72 \mathrm{~h}$ before being transferred to $25 \mathrm{C}$ for $72 \mathrm{~h}$. Seeds were also chilled in their Plexiglas units at $2.5 \mathrm{C}$ for $0,24,48,72$, or $96 \mathrm{~h}$ before being transferred to $25 \mathrm{C}$ for $72 \mathrm{~h}$. The subsequent elongation of the radicle and the number of lateral roots formed after the imposition of temperature treatments were measured every $24 \mathrm{~h}$ for $72 \mathrm{~h}$. In another series of experiments, a comparison was made between subsequent inhibition of radicle elongation and induction of lateral roots after chilling at 2.5 $\mathrm{C}$ from 0 to $192 \mathrm{~h}$.

Heat-shock induced chilling tolerance. Germinated seeds with radicles at the sensitive 5-mm length were heat-shocked as de- scribed above. The heat-shocked seeds were kept at $25 \mathrm{C}$ for $2 \mathrm{~h}$ before being transferred to new Plexiglas plates assembled as before. The Plexiglas units were then either kept at $25 \mathrm{C}$ for $72 \mathrm{~h}$, or chilled at $2.5 \mathrm{C}$ for $72 \mathrm{~h}$ before being kept at $25 \mathrm{C}$ for $72 \mathrm{~h}$.

Experimental design. All experiments were repeated at least three times with similar results. In each experiment, each treatment was applied to at least two plates containing 15 seeds each. Experiments used a completely randomized design and data were analyzed by analysis of variance. When significant differences were detected, LSD values were calculated at $P=0.05$.

\section{Results}

Relationship between radicle length and chilling sensitivity. Germinated corn, cucumber, mung bean, and tomato seeds with 5to 7-mm-long radicles were more chilling sensitive that the same seeds with 1-mm-long radicles (Fig. 2). Chilling for $72 \mathrm{~h}$ inhibited subsequent elongation of 1-mm-long cucumber radicles by $2 \%$ while having a $20 \%$ effect on corn, mung bean, and tomato radicles. Subsequent radicle elongation in corn, mung bean, and tomato seeds chilled when the radicle was $7 \mathrm{~mm}$ long was inhibited $60 \%$ to $67 \%$, while it was inhibited $85 \%$ in cucumber and okra at the same stage of growth. In contrast to this change in chilling sensitivity with radicle length, the subsequent elongation of okra radicles was inhibited about $80 \%$ at radicle lengths from 1 to $7 \mathrm{~mm}$.

Effects of temperature and duration of exposure on subsequent elongation. Radicles of corn grew the fastest and were the longest of the four species after $72 \mathrm{~h}$ at $25 \mathrm{C}$, followed by tomato, mung bean, and okra (Fig. 3). None of the species showed any significant radicle elongation at 2.5 or $5 \mathrm{C}$ for up to $72 \mathrm{~h}$. At $7.5 \mathrm{C}$, corn and tomato radicles elongated $44 \%$ and $27 \%$, respectively, after $72 \mathrm{~h}$, while those of mung bean and okra showed no significant elongation. Elongation increased exponentially for corn and okra as the temperature increased from 7.5 to $15 \mathrm{C}$. Between 12.5 and $15 \mathrm{C}$ radicle length increased $56 \%$ and $92 \%$ for corn and okra while it increased only $8 \%$ and $29 \%$ for mung bean and tomato. In contrast, radicle elongation for mung bean and tomato at these temperatures increased linearly. The equation for radicle length of mung bean as affected by temperature after $72 \mathrm{~h}$ was length $=0.346+(0.328 \times$ temp); $r^{2}=0.996$. For tomato it was length $=-0.812+(0.192 \times$ temp); $r^{2}=0.998$.

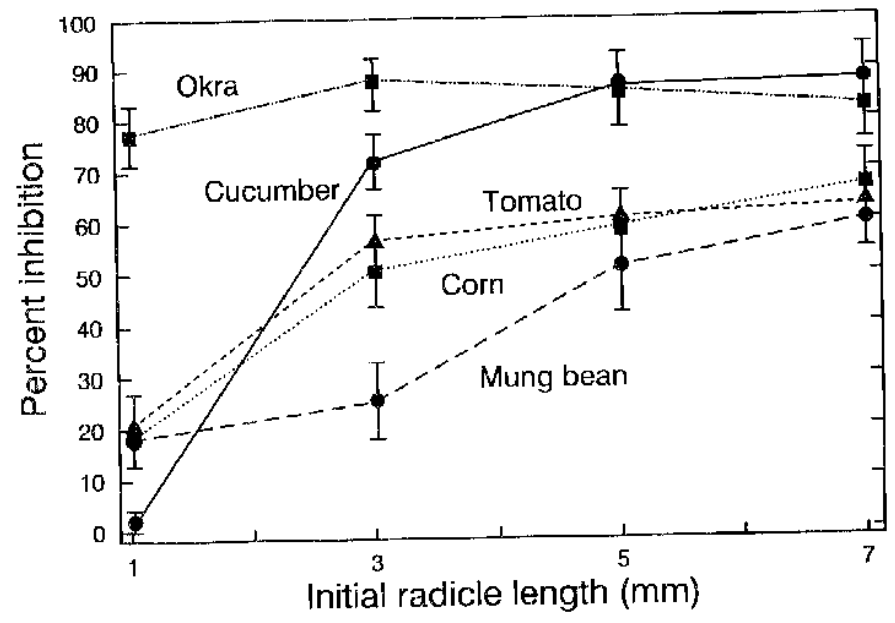

Fig. 2. Relationship between radicle lengths at the time of chilling for $72 \mathrm{~h}$ at 2.5 $\mathrm{C}$ and subsequent radicle elongation for $72 \mathrm{~h}$ at $25 \mathrm{C}$. Data are expressed as percent inhibition of elongation compared to the unchilled control. The vertical bars represent the standard deviations about the means $(n=30)$. 

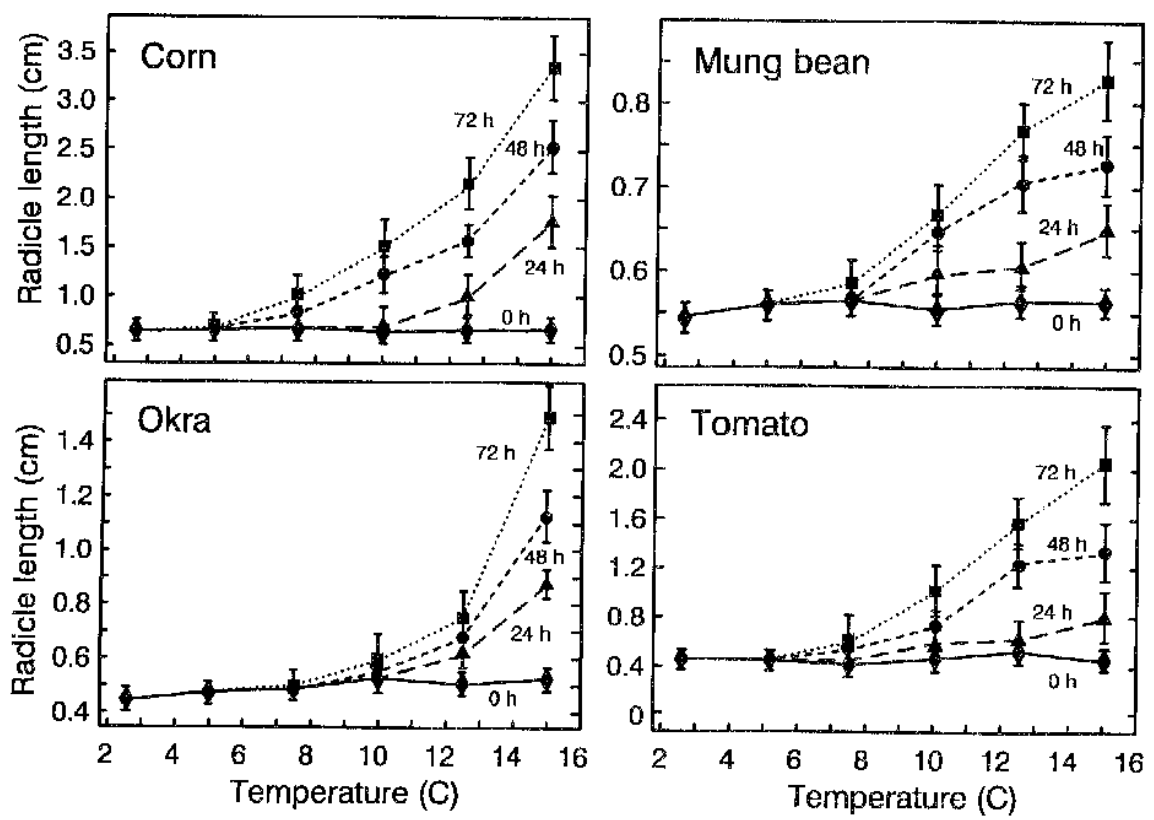

tion of nonchilled radicles. The protection afforded by heat shock was greatest for corn and mung bean, where a $10 \mathrm{~min}$ exposure to 45 $\mathrm{C}$ reduced subsequent inhibition of radicle elongation from $54 \%$ to $27 \%$ for corn and from $83 \%$ to $37 \%$ for mung bean. Although nonchilled tomato radicles did not exhibit a reduction in elongation after any duration of heat shock, the combination of $>4$ min of heat shock with chilling drastically reduced subsequent elongation. A slight level of chilling tolerance was conferred to tomato radicles by 4 min of heat shock, which reduced chillinginduced inhibition of elongation from 54\% to $36 \%$.

Unlike the other three species and cucumber (Rab and Saltveit, 1996), heat shocks did not confer any chilling tolerance to okra (Fig. $6)$. Even when the treatment regimes were expanded to include heat shocks at 45 and 50 $\mathrm{C}$ for up to $10 \mathrm{~min}$ and the duration of chilling was reduced from 96 to $72 \mathrm{~h}$, no significant

Fig. 3. Effects of temperature on the elongation of seedling radicles. All radicles were initially $5 \mathrm{~mm}$ long. The vertical bars represent the standard deviations about the means $(n=30)$.

Keeping germinated seeds with 5-mm-long radicles at $2.5 \mathrm{C}$ for up to $96 \mathrm{~h}$ significantly reduced subsequent radicle elongation (Fig. 4). Corn radicles were the least affected by the chilling, but even they showed reduced elongation. Radicle elongation in tomato was reduced by $72 \mathrm{~h}$ and stopped for $24 \mathrm{~h}$ by $96 \mathrm{~h}$ of chilling. The lag extended to $48 \mathrm{~h}$ for mung bean exposed for 72 or $96 \mathrm{~h}$, while shorter exposures of 24 to $48 \mathrm{~h}$ curtailed elongation for $24 \mathrm{~h}$. Radicle elongation was completely prevented in okra by $96 \mathrm{~h}$ chilling and significantly reduced by $72 \mathrm{~h}$.

While all species were able to resume some radicle elongation after 24 to $72 \mathrm{~h}$ of chilling, the rate of elongation was significantly reduced, at least for a while (Fig. 4). The rates of radicle elongation from 48 to $72 \mathrm{~h}$ after chilling were similar for mung bean exposed to $0,24,48$, and $72 \mathrm{~h}$ of chilling and for tomato exposed for all durations. In contrast, exposure to even $24 \mathrm{~h}$ of chilling caused a significant reduction in the rate of radicle elongation that persisted during the entire $72-\mathrm{h}$ recovery period for corn and okra.

The effect of chilling on subsequent radicle elongation and on lateral root formation was significantly different among species (Fig. 5). For germinating corn seeds, radicle length and the number of lateral roots steadily decreased at the chilling duration increased. The other species also showed a steady decline in subsequent radicle elongation as the duration of chilling increased, but they differed from corn in that the number of lateral roots formed remained constant or increased during the initial increases in chilling duration.

Heat-shock induced chilling tolerance. Exposure to $45 \mathrm{C}$ for up to $10 \mathrm{~min}$ conferred some level of chilling tolerance to all species except okra; however, the response was variable (Fig. 6). These heat treatments had no significant effect on the subsequent elonga- increase in chilling tolerance was observed in okra radicles.

\section{Discussion}

The chilling sensitivity of germinated cucumber, corn, tomato, and mung bean seeds was greater when radicles were 5 to $7 \mathrm{~mm}$ long than when radicles were $1 \mathrm{~mm}$ long. In contrast, the chilling sensitivity of okra seedlings remained consistently high for radicles from 1 to $7 \mathrm{~mm}$ long. Chilling caused a $2 \%$ inhibition of subsequent radicle elongation in cucumber seedlings when the radicle was 1 $\mathrm{mm}$ long, but a $18 \%$ to $21 \%$ inhibition for corn, mung bean, and tomato seedlings at the same stage of growth. Radicle elongation in okra was inhibited at about $77 \%$ for initial radicle lengths of 1

Fig. 4. Effects of chilling at $2.5 \mathrm{C}$ for 0 to $96 \mathrm{~h}$ on subsequent radicle elongation at 25 C. All radicles were initially $5 \mathrm{~mm}$ long. The vertical bars represent the standard deviations about the means $(\mathrm{n}=30)$.
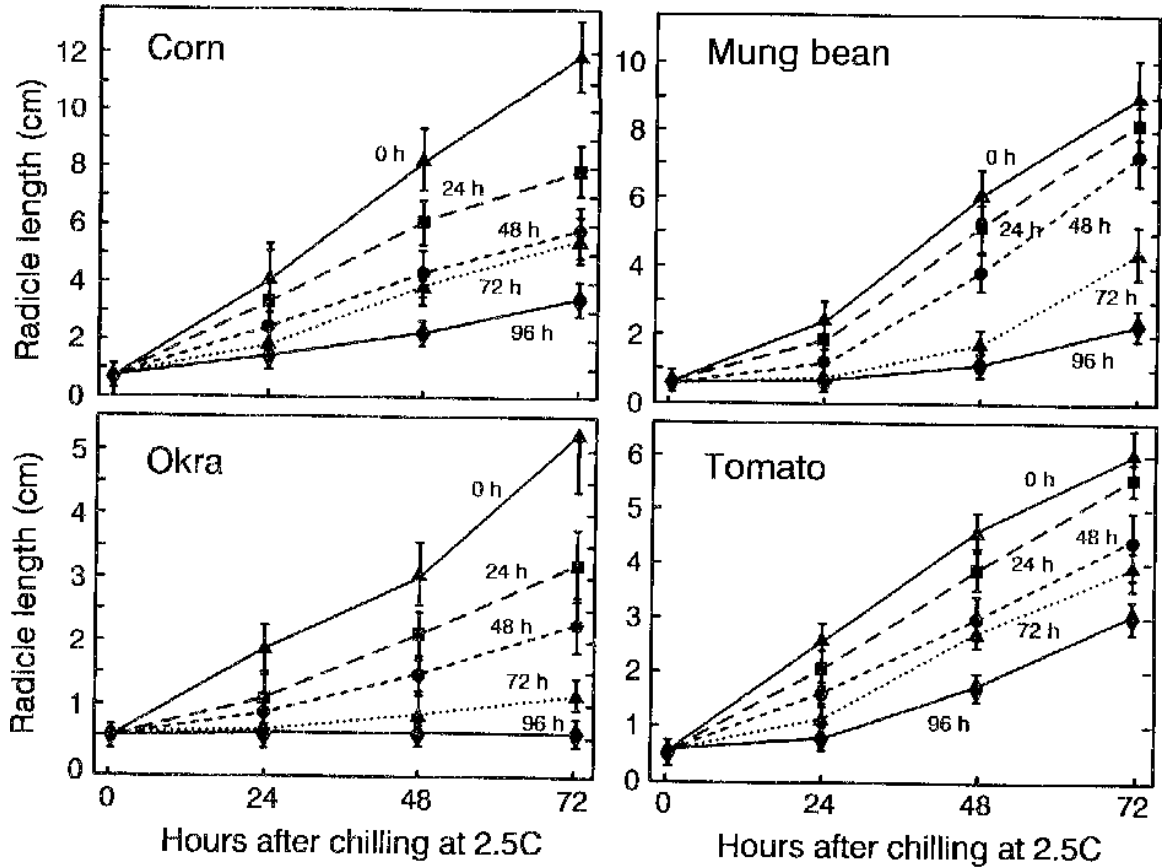

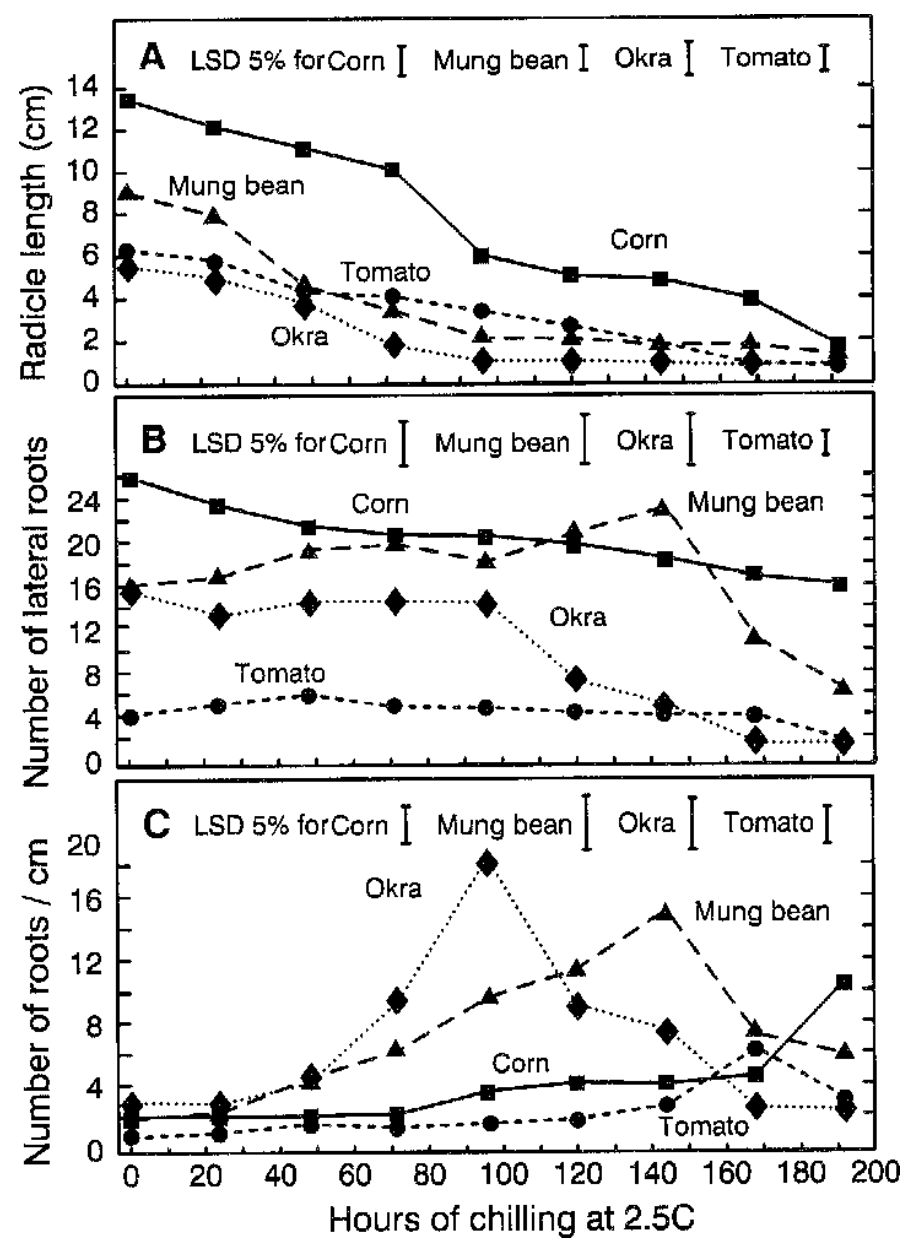

Fig. 5. Effects of duration of chilling at 2.5 C on (A) subsequent radicle elongation at $25 \mathrm{C}$ for $72 \mathrm{~h}$, on (B) subsequent formation of lateral roots after $144 \mathrm{~h}$ at $25 \mathrm{C}$, and on $(\mathbf{C})$ number of lateral roots formed per $\mathrm{cm}$ of root length. All radicles were initially $5 \mathrm{~mm}$ long. The vertical bars represent the standard deviations about the means $(n=30)$.

to $7 \mathrm{~mm}$. (Fig. 2). While okra and cucumber were at the opposite extremes of chilling sensitivity for seeds with 1-mm-long radicles,
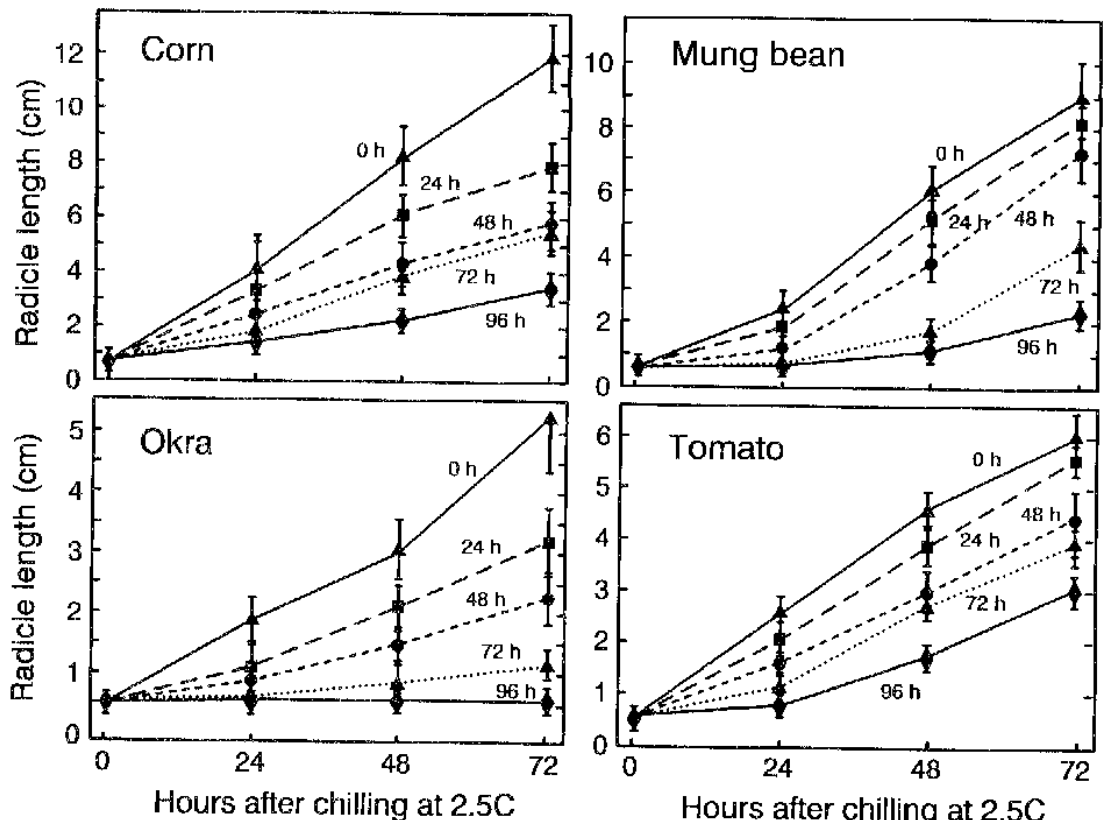

they were both more chilling sensitive than the other species when radicles were 5 to $7 \mathrm{~mm}$ long. Although the rate of elongation tends to increase as radicles increase from 1 to 3 or $5 \mathrm{~mm}$ in length, this difference in elongation rate probably does not account for differences in chilling sensitivity since this pattern of change was also typical of okra radicles (data not shown). The initial chilling tolerance of corn, tomato, mung bean, and especially cucumber radicles depends on the stages of development and perhaps on a chilling tolerance factor that may dissipate with the development of the radicle (Jennings and Saltveit, 1994b).

All species were able to grow at $15 \mathrm{C}$, but significantly slower radicle elongation was observed for mung bean at this temperature (Fig. 3). This slower rate of elongation was odd, since mung bean was relatively chilling tolerant (Fig. 2). In other experiments in which longer radicles (e.g., $1.5 \mathrm{~cm}$ ) were exposed to 12.5 or $15 \mathrm{C}$, the inhibition of radicle elongation was less severe than observed in these experiments (data not shown).

Variations in chilling sensitivity among species was also evident when radicles were chilled at $2.5 \mathrm{C}$ for various durations of time. Chilling for $24 \mathrm{~h}$ caused a significant decrease in subsequent radicle elongation for corn and okra but not for tomato or mung bean (Fig. 4). The severity of injury increased with increasing chilling duration, but, unlike cucumber (Rab and Saltveit, 1996), chilling was not lethal even at $96 \mathrm{~h}$, except for okra.

The initial inhibition of radicle elongation when exposed to modest chilling cannot predict the fate of the root tip subjected to extended chilling. Corn, for example, showed decreased radicle elongation with $24 \mathrm{~h}$ of chilling, but the root tip survived $192 \mathrm{~h}$ of chilling. In contrast, tomato and mung bean initially appeared less sensitive based on their response to $24 \mathrm{~h}$ of chilling, but exposure to $192 \mathrm{~h}$ of chilling resulted in the death of the root tips. Mung bean, however, was able to regenerate an apical root meristem even after $192 \mathrm{~h}$ of chilling.

Root tips are more sensitive to chilling than the rest of the root (Rab and Saltveit, 1996). This differential sensitivity among regions of the root was observed for all species studied. For example, the length of the corn radicle after $72 \mathrm{~h}$ at $25 \mathrm{C}$ following chilling decreased as the duration of chilling increased, but the development of lateral roots was affected only slightly as the duration of chilling increased to 192 $\mathrm{h}$ (Fig. 5). However, the development of lateral roots in okra was not affected by $96 \mathrm{~h}$ of chilling but decreased markedly with 120 or 144 $\mathrm{h}$ of chilling. Further increases in chilling resulted in a failure of the radicle to develop lateral roots. The chilling-induced decrease in the number of lateral roots formed in okra occurred with less chilling than for the other species and is another example of the extreme sensitivity of this species. The chilling sensitivity of the subapical region, as evident from the decrease in the number of lateral roots formed, is similar to that of cucumber (Rab and Saltveit, 1996) and is consistent with the level of chilling sensitivity shown for cucumber and okra (Fig. 2). Differences in chilling sensitivity can also be seen between mung bean and tomato (Figs. 2 and 5). In these species, lateral root development did not cease even after $192 \mathrm{~h}$ of chilling.

Fig. 6. Effects of heat shock at $45 \mathrm{C}$ for up to $10 \mathrm{~min}$ on the subsequent radicle elongation of germinated seeds chilled at $2.5 \mathrm{C}$ for $96 \mathrm{~h}$. All radicles were initially $5 \mathrm{~mm}$ long. The vertical bars represent the standard deviations about the means $(\mathrm{n}=30)$. 
Our data suggest that an inhibition of radicle elongation, not death of the root apical meristem, can stimulate the induction of lateral roots (Fig. 5). This is in contrast to the hypothesis that death or damage of the root apical meristem may trigger the development of lateral roots over a short region of the root (Creencia and Bramlage, 1971; Minorsky, 1985). The relationship between radicle length and lateral root development in chilled tissue was more evident in tomato and mung bean. In both of these species, chilling seems to act as an inducer for lateral root development. In mung bean, for example, the number of lateral roots increased with increasing chilling duration up to $144 \mathrm{~h}$, but then it suddenly declined as chilling duration continued to increase. A similar trend can also be seen in tomato in which an initial increase in the number of lateral roots was followed by a decrease to a number that remained constant for up to $168 \mathrm{~h}$ and then decreased significantly.

This brief survey of a few chilling sensitive plants has identified similarities and differences among species and stages of root growth. Differences in the chilling sensitivity of radicles among species and with elongation furnishes us with genetically diverse (i.e., radicles among species) and similar (i.e., elongated radicles within a specie) material to study the basic nature of chilling injury. The initial chilling tolerance of germinated seeds (i.e., seeds with 1-mm-long radicles), its loss upon radicle elongation (i.e., seeds with 5-mm-long radicles), and its reacquisition with heat shock in some species can provide us with model systems to study chilling sensitivity and the induction of tolerance. The uniform chilling sensitivity of different length okra radicles and the inability of heat shock to induce chilling tolerance in this specie are interesting phenomena that differ significantly from the other four species tested. Additional Malvaceous species and cultivars should be tested to see if these differences are general characteristics for this specie or whether it extends to the genus or family.

\section{Literature Cited}

Burke, J.J., J.L. Hatfield, R.R. Klein, and J.F. Mullet. 1985. Accumulation of heat-shock proteins in field grown cotton. Plant Physiol. 78:394-398. Bramlage, W.J. 1982. Chilling injury of crops of temperate origin. HortScience 17:165-168.

Chen, Y.M., S. Kamisaka, and Y. Masuda. 1986. Enhancing effects of heat-shock and gibberellic acid on the thermotolerance of etiolated Vigna radiata. I. Physiological aspects of thermotolerance. Physiol. Plant. 66:595-601.

Cabrera, R.M. and M.E. Saltveit. 1990. Physiological response to chilling temperatures of intermittently warmed cucumber fruit. J. Amer. Soc
Hort. Sci 115:256-261.

Cabrera, R.M., M.E. Saltveit, and K. Owens. 1992. Cucumber cultivars differ in their response to chilling temperatures. J. Amer. Soc Hort. Sci 117:802-807.

Collins, G.G., X. Nie, and M.E. Saltveit. 1993. Heat-shock increases chilling tolerance of mung bean hypocotyl tissue. Physiol. Plant. 89:117-124.

Collins, G.G., X. Nie, and M.E. Saltveit. 1995. Heat-shock proteins and chilling injury of mung bean hypocotyls. J. Expt. Bot. 46:795-802.

Creencia, R.P. and W.J. Bramlage. 1971. Reversibility of chilling injury to corn seedlings. Plant Physiol. 47:389-392.

Jennings, P. and M.E. Saltveit. 1994a. Temperature and chemical shocks induce chilling tolerance in germinating Cucumis sativus (cv. Poinsett 76) seeds. Physiol. Plant. 91:703-707.

Jennings, P. and M.E. Saltveit. 1994b. Temperature effects on imbibition and germination of cucumber (Cucumis sativus) seeds. J. Amer. Soc Hort. Sci 119:464-467.

Kapitsimadi, C.M., O. Roeggen, and H. Hoftun. 1991. Growth of four cucumber (Cucmis sativus) cultivars at suboptimal temperatures and storage behavior of their fruits at different temperatures. Acta Hort. 258:375-383.

Lafuente, M.T., A. Belver, M.G. Guye, and M.E. Saltveit. 1991. Effect of temperature conditioning on chilling injury of cucumber cotyledons. Plant Physiol. 95:443-449.

Lyons, J.M., D. Graham, and J.K. Raison. 1979. Low temperature stress in crop plants. Academic Press, New York.

Lurie, S. and J.D. Klein. 1991. Acquisition of low-temperature tolerance in tomatoes by exposure to high-temperature stress. J. Amer. Soc Hort. Sci 116:1007-1012.

Mansfield, M.A. and J.L. Key. 1987. Synthesis of low molecular weight heat-shock proteins in plants. Plant Physiol. 84:1007-1017.

Meyer, Y. and Y. Chartier. 1983. Long-lived and short-lived heat-shock proteins in tobacco mesophyll protoplasts. Plant Physiol. 72:26-32.

Minorsky, P.V. 1985. An heuristic hypothesis of chilling injury in plants: a role for calcium as the primary physiological transducer of injury. Plant Cell Environ. 8:75-94.

Nover, L. and K.D. Scharf. 1984. Synthesis, modification and structural binding of heat-shock proteins in tomato cell culture. Eur. J. Biochem. 139:303-313.

Rab, A. and M.E. Saltveit. 1996. Differential chilling sensitivity in cucumber (Cucumis sativus cv. Poinsett 76) seedlings. Physiol. Plant. (In press.)

Saltveit, M.E. 1991. Prior temperature exposure affects subsequent chilling sensitivity. Physiol. Plant. 82:529-536.

Saltveit, M.E. and L.L. Morris. 1990. Overview of chilling injury of horticultural crops. In: C.Y. Wang (ed.). Chilling injury of horticultural crops. CRC Press, Boca Raton, Fla.

Vierling, E. 1990. The role of heat-shock proteins in plants. Annu. Rev. Plant Physiol. Plant Mol. Biol. 42:579-620. 